\title{
A CRÍTICA NIETZSCHIANA AOS ERUDITOS E A SUA PEDAGOGIA DEGENERADA NO GYMNASIUM ALEMÃO
}

\author{
The nietzschean criticism to te erudites and their degenerated pedagogy in german \\ gymnasium
}

Tiago Xavier

\begin{abstract}
RESUMO: $O$ presente trabalho pretende mostrar que com a multiplicação dos estabelecimentos de ensino na Alemanha do século XIX, o ensino emancipador, tão importante para combater os pensamentos rasteiros, impróprios para 0 voo, foi perdendo espaço para um saber científico, utilitário (lucrativo), destruindo as raízes das forças mais elevadas e mais nobres da cultura alemã, subvertendo a ordem natural no reino do intelecto. Diante de toda essa decadência, Nietzsche aparece como crítico, iconoclasta e intempestivo que reivindica a golpes de martelo uma renovação e purificação destes estabelecimentos, abrindo espaço para que as forças mais sadias vindas da antiguidade clássica (Greco-romana) dessem as armas necessárias para a peleja contra a barbárie que se cristalizava em seu tempo.
\end{abstract}

Palavras-chave: Nietzsche. Erudito. Cientificismo. Educação. Cultura. Gênio.

ABSTRACT: This paper intends to show that along with the multiplication of educational establishments in the 19th century Germany, the emancipatory teaching which is so important to neutralize the poor thoughts, unsuitable for higher flights, has lost room to a scientific and utilitarian (profitable) knowledge, destroying the roots of the higher and nobler German culture forces, subverting the natural order in the reign of intellect. Faced with all this decadence, Nietzsche appears as a critical, iconoclastic and untimely man who claims with hammer blows for renovation and purification of these establishments, opening space for healthier forces coming from classical (Greco-Roman) antiquity to give the necessary weapons to fight the crystallized barbarism of his days.

Keywords: Nietzsche. Erudite. Scientism. Education. Culture. Genius.

\section{INTRODUÇÃO}

A crítica que Nietzsche fará aos eruditos e a sua pedagogia degenerada no gymnasium alemão se dará ao fato de não haver nestes indivíduos, engajamento com a construção de um saber capaz de unir pensamento e vida. 
No primeiro momento do presente trabalho, mostraremos o início da ofensiva do filósofo de Röcken contra os eruditos por eles estarem preocupados apenas com ninharia, detendo uma espécie de conhecimento que não passava de historicismo que sufocava o presente - deixando os homens incapazes de parir os seus próprios pensamentos que thes proporcionaria um conhecimento de desdobramento e expansão da vida.

Após esse primeiro momento, apontaremos que por conta da multiplicação dos estabelecimentos de ensino, a necessidade de se fabricar profissionais para ocupá-los aumentou freneticamente a ponto da qualidade não mais ser uma prioridade de formação.

No terceiro momento, explicitaremos que a péssima metodologia dos eruditos no Gymnasium alemão contribuiu para a enfermidade cultural, uma vez que a escrita e a língua alemã estavam sendo profanadas e vulgarmente ensinadas aos alunos de forma tão medíocre, que se assemelhava à linguagem jornalística da época: sem rigor linguístico e sem originalidade.

Após esse momento, destacaremos que Nietzsche propõe a ideia de que o ginásio objetive a cultura clássica, pois a reforma da educação das instituições de ensino na Alemanha se daria pelo próprio ginásio, partindo do gênio grego o processo de transformação que contribuiria para a supressão dos pensamentos rasteiros presentes nos estabelecimentos de ensino.

Por fim, afirmaremos que a posição contrária de Nietzsche aos homens de erudição, tinha como objetivo subjugar a filosofia de brinquedo e a pseudofilosofia que não contribuíam para o combate ao falso saber que se cristalizava em seu tempo.

\section{NIETZSCHE CONTRA OS ERUDITOS}

Em 1872, o jovem Nietzsche elabora cinco conferências sobre a educação na sociedade acadêmica ${ }^{1}$, apontando os perigos e os problemas que haveriam de surgir por causa da má qualidade de ensino que estava sendo inserido na educação

\footnotetext{
${ }^{1}$ Das cinco conferências que Nietzsche pretendia proferir, apenas três são apresentadas; um problema de garganta fez com que ele não apresentasse as outras duas.
} 
de sua época que não capacitava os cidadãos a terem uma visão de lince ${ }^{2}$ que os ajudasse a perceber que uma boa educação só poderia subsistir se o povo preservasse o brilho de sua cultura, lutando e defendendo-a de toda e qualquer espécie de ninharia oferecida pelos eruditos ${ }^{3}$.

O conhecimento desses indivíduos, na visão de Nietzsche, não passava de historicismo que sufocava o presente ${ }^{4}$, deixando os homens inanes: incapazes de parir os seus próprios pensamentos que superariam o vício imitador de pensamentos alheios e, consequentemente, garantiria um conhecimento de expansão da vida.

Essa expansão só se daria por meio do conhecimento puro, característico da filosofia verdadeira, e não do conhecimento aplicado, característico do saber técnico. Pois enquanto o primeiro contribuía para a natureza do intelecto, ajudando os indivíduos na construção dos seus próprios pensamentos por abstração em prol da expansão da vida enquanto seres humanos, o segundo só fazia preencher a mente humana com informações e ideias que não foram antes vivenciadas nem experimentadas.

Por isso o conhecimento para a expansão da vida não deveria ser confundido com os saberes técnicos que passam a ter, em primeira instância, utilidade para a especialização que visa à produção de profissionais especializados.

Por não terem a capacidade de construir o conhecimento que proporcionasse a expansão da vida, Nietzsche via os eruditos como indivíduos doentes, estéreis, infecundos, contaminados pela impostura e busca desenfreada de uma erudição que não contribuía para que os homens se tornassem autores da sua própria história, permanecendo na impossibilidade de construir e preservar uma cultura que proporcionasse a verdadeira educação ${ }^{5}$ emancipatória que garantiria aos homens

\footnotetext{
${ }^{2}$ Pessoa que tem uma visão excepcional. A expressão lince não tem nada a ver com o animal mamífero, carnívoro, da família dos Felídeos. É uma expressão originária de Linceu (herói da mitologia grega). Segundo a lenda, Linceu tinha visão formidável.

${ }^{3}$ Indivíduos que tinham um déficit exacerbado de conhecimento para a vida, preocupando-se apenas com o lucro, comportando-se como mercenários sedentos por pecúnia e desengajados com a construção de um saber que unisse o pensamento e a vida.

${ }^{4}$ Embora Nietzsche seja um grande crítico da História, em especial da história da Filosofia, por entender que muitos valores que atravessaram séculos e que chegaram até os seus dias não foram questionados, dissecados e problematizados, ocultando por muito tempo a sua real face, negue 0 conhecimento histórico na sua totalidade. Para ele tal conhecimento só é saudável quando se pode aplicá-lo na vida em prol da expansão da mesma, e não como sufocamento e aniquilação dela.

${ }^{5}$ Rosa Maria Dias, em sua obra Nietzsche Educador, diz que "educação e cultura para Nietzsche são inseparáveis. Não existe cultura sem um projeto educativo, nem educação sem uma cultura que a apoie" (1991, p. 17).
} 
mais ousados um intelecto superior ao dos indivíduos degenerados, possibilitando o valor da existência, como nos mostra Lima:

Nietzsche espera trazer à tona o valor da existência, que foi perdido pelo apreço sem medida ao conhecimento. O filósofo almeja fazer com que o homem lembre-se de si mesmo, sobretudo como um criador, um artista. (2012, p. 53, grifos do autor).

Esse lembrar-se de si não significa dizer que seja um modelo de pensamento que transmita ao homem o egoísmo extremo, transfigurando-o em ser demasiado individualista; mas um pensamento capaz de mostrar que é possível, por meio de uma cultura fecunda, reconhecer o valor da existência, não se deixando seduzir pela busca exacerbada do conhecimento científico ${ }^{6}$, pois essa postura proporcionaria ao homem ser o oposto dos eruditos da cultura; tornando-se perspicaz e denunciador da decadência existente em seu tempo, e buscando, "a partir de si mesmo, sua missão no engendramento da cultura em seu todo" (LIMA, 2012, p. 53, grifo do autor).

A erudição dos eruditos, na ótica de Nietzsche, deixava os homens debilitados, cegos, surdos e mudos, ficando na incapacidade de falar por si próprios ou buscar em si mesmos o sentido da sua existência no mundo, vivendo "uma vida desprovida de sentido, sem liberdade e sem ousadia para ter seus próprios pensamentos" (LIMA, 2012, p. 55).

Por esses motivos, o filósofo de Röcken via os eruditos como criaturas que contribuíam para o naufrágio da cultura, suprimindo ferramentas que ajudavam os indivíduos a criarem, a partir de si mesmos, pontes que conduziriam para além do fastio criativo que os esvaziavam e os deixavam na incapacidade de "questionar seu próprio ser" (LIMA, 2012, p. 54) e a erudição estéril proferida em seus ouvidos.

\section{MULTIPLICAÇÃO DOS ESTABELECIMENTOS DE ENSINO}

\footnotetext{
${ }^{6}$ Nietzsche se posiciona contra o cientificismo por entender que, além dele ser um conhecimento que fragmenta a vida - diferentemente da filosofia, que liga o saber à arte, afirmando a vida em seu conjunto -, o mesmo carrega o instinto de uma suposta verdade que mata a cultura e o seu sistema poético de imagens míticas, repleto de ilusões sadias para a vida. Refletindo sobre isso, Rosa Maria Dias diz que "a vida tem necessidade de um olhar que a embeleza, pois ela só é possível 'pelas miragens artísticas'. O homem da ciência retira o véu benfazejo que cobre a vida e a embeleza, e isso tudo em nome do real e da verdade" (1991, p. 83). E acrescenta dizendo que "a ciência, ao querer reconhecer a vida custe o que custar, 'destrói as ilusões' que ajudam o homem a viver" (Idem, ibidem, p. 102). Por fim, diz que "Nietzsche, ao criticar a ciência, não visa aniquilá-la, mas conter seus excessos. A vida em pedaços garante menos vida para o futuro do que a vida enfeitiçada por algumas quimeras" (Idem, ibidem, p. 83).
} 
Com a multiplicação dos estabelecimentos de ensino na Alemanha, fomentada pelo Estado, a necessidade de se fabricar profissionais para ocupá-los aumentava freneticamente a ponto da qualidade não mais ser uma prioridade de formação, uma vez que era o próprio Estado que pasteurizava os indivíduos a quem a natureza não concedeu dons para uma autentica cultura, e que chegaram mesmo à pretensão de fazer as vezes de mestres da cultura, só porque os impulsiona a necessidade de ganhar o pão de cada dia e porque o excessivo número de escolas exigia para si um excessivo número de mestres (NIETZSCHE, 2012a, p. 112-113).

Esses indivíduos destruíam as raízes mais elevadas e mais nobres da cultura, interferindo no surgimento do gênio ${ }^{7}$ : o jogo completo das cores de todas as forças particulares, o libertador da esfera mutante da instantaneidade que religa seu povo à eternidade. (NIETZSCHE, 2012a, p. 106).

Uma vez que o Estado era o fomentador e o responsável pela multiplicação dos estabelecimentos de ensino, o mesmo aparecia como o mistagogo da cultura e, ao mesmo tempo em que perseguia seus próprios fins, obrigava a todos os seus servidores a só se apresentarem diante dele munidos da luz da cultura universal do próprio Estado (NIETZSCHE, 2012a, p. 115).

Sob essa luz turva, os profissionais deveriam reconhecer nele (o Estado) o objetivo supremo, como aquele que recompensa todos os seus esforços na direção da cultura (NIETZSCHE, 2012a, p. 115).

A ideia de cultura universal do Estado era a extensão e ampliação máxima, redução e enfraquecimento da cultura, pois era por meio disso que ela passaria a ter utilidade, como nos mostra Nietzsche:

O máximo de conhecimento e cultura possível - portanto o máximo de produção e necessidades possível -, portanto o máximo de felicidade possível: - eis mais ou menos a fórmula. Temos aqui, como objetivo e fim da cultura a utilidade, ou, mais exatamente, o lucro, o maior ganho de dinheiro possível. (2012a, p. 72).

\footnotetext{
${ }^{7}$ Rosa Maria Dias define o gênio nietzschiano como "a grande natureza contemplativa armada para a criação eterna. A extensão da alma, a força da imaginação, a atividade do espírito, a abundância e a irregularidade das emoções - tudo isso compõe o caráter do gênio. [...] o gênio está além das motivações interesseiras e interessadas e tem uma visão de conjunto do conhecimento e da vida. É um 'homem-destino', um instrumento do fundo criador da vida, investido de uma missão cósmica de conservar a vida e fazê-la frutificar" (1991, p. 81).
} 
Por meio dessa ideia, o Estado despertava nos indivíduos "a impressão de que a cultura estendida à maioria dos homens não era senão um meio para uma minoria obter a felicidade na terra" (NIETZSCHE, 2012a, p. 74).

Para Nietzsche, essa pretensão do Estado nada mais era que pura barbárie, uma vez que o fomentador se colocava à frente da cultura, impondo suas ordens e fazendo da mesma uma serva geradora de lucros que lhe garantiria a existência e hegemonia.

Isso despertava nos espíritos mais nobres verdadeiro repúdio, e não sentimento de admiração e reconhecimento, como sentiram os gregos pelo Estado:

\begin{abstract}
Os gregos tinham pelo Estado sentimento poderosos de admiração e de reconhecimento, quase escandaloso para o homem moderno. $O$ Estado não era para aquela cultura um guarda de fronteiras, um regulador, um superintendente, mas o companheiro de viagem, e o companheiro de andar vigoroso, forte, disposto ao combate, que escoltava através das rudes realidades o seu amigo mais nobre e, por assim dizer, quase divino, pelo qual se tinha admiração e do qual ele recebia em troca o reconhecimento. (NIETZSCHE, 2012a, p. 116).
\end{abstract}

Por tudo isso, Nietzsche desaprovava o Estado por entender que o mesmo não ajudava em nada a educação e a cultura, uma vez que seu objetivo era persuadir os indivíduos de que eles próprios encontrariam o caminho guiado pela estrela do próprio Estado.

\title{
4. A EDUCAÇÃO DEGENERADA NO GYMNASIUM ALEMÃO ENQUANTO FOMENTADORA DA ENFERMIDADE CULTURAL
}

$\mathrm{Na}$ ótica nietzschiana, tanto a multiplicação dos estabelecimentos de ensino, como também, a péssima metodologia dos eruditos no Gymnasium alemão ${ }^{8}$, contribuíam para a enfermidade cultural de sua época, uma vez que neste recinto a língua alemã estava sendo profanada e vulgarmente ensinada aos alunos de forma tão medíocre, que se assemelhava à linguagem jornalística da época: sem rigor linguístico e sem originalidade. Por isso, "aquele que não chega ao sentimento de um dever sagrado para com ela, este não tem mais em si o germe que convém a uma cultura superior" (NIETSZCHE, 2012a, p. 81).

\footnotetext{
${ }^{8}$ Equivale aos antigos ginásios e colegial alemão, que se comparado ao currículo brasileiro, podemos defini-lo como ensino médio.
} 
A originalidade, a beleza e o rigor linguístico eram para Nietzsche elementos importantíssimos que deveriam estar presentes no ginásio por meio das leituras clássicas alemãs, latinas e gregas - que, ao serem experimentadas pelos alunos, os afastariam do ar poluído e pesado dos escritos jornalísticos que não contribuíam para a vitalidade criativa e intelectual dos mesmos ${ }^{9}$.

Por conta da não existência do rigor linguístico no ginásio, o filósofo de Röcken via esse lugar como um pseudo-estabelecimento de ensino, uma vez que ele não formava homens para a cultura, mas unicamente para um saber estúpido e paralisador das virtudes humanas.

Essa paralisia estava relacionada ao ensino antipedagógico que incitava os alunos a descreverem sua própria vida e seu próprio desenvolvimento, forçando-os a desenvolverem o mais depressa possível uma personalidade autônoma que estava longe de seu alcance pelo fato de ainda estarem imaturos, como nos mostra o próprio Nietzsche ao se referir a esta metodologia que induzia os alunos a manifestarem

o seu juízo sobre as obras poéticas, ou fazer entrar personagens históricos na forma coagulada de uma pintura de caracteres, ou a expor de forma autônoma graves problemas éticos, ou mesmo, invertendo o foco, a esclarecer o seu próprio desenvolvimento e fazer de si mesmo um resumo crítico: em suma, todo um mundo de tarefas que exige uma reflexão profunda se abre diante de um jovem perplexo, que até aí era quase inconsciente, e que é abandonado à sua decisão. (2012a, p. 85).

Quando isso acontecia, o estudante não era capaz de sentir as etapas da vida de forma gradativa e natural ${ }^{10}$, pois, a evolução que deveria ser respeitada segundo as etapas da natureza, era violada de forma arbitrária por uma metodologia de caráter nocivo aos espíritos ainda não desenvolvidos dos alunos, fazendo nascer na mente dos mesmos, de forma ingênua, a ideia de estarem prontos a compreender e a criticar os clássicos - assemelhando-se ao caráter repulsivo do jornalismo estético da época que não passava de uma impertinente barbárie.

\footnotetext{
${ }^{9}$ Nietzsche repudiava o espírito jornalístico de sua época por entender que ele nada mais era que o erudito corrompido, preconizador e disseminador de uma arte literária degenerada, inautêntica, atada por jargões e ideias que não contribuíam para a ascensão emancipadora dos homens (NIETZSCHE, 2012a, p. 98).

${ }^{10}$ Infância, adolescência, mocidade, e assim por diante.
} 
Indagando acerca desse assunto, Rosa Maria Dias dirá que toda a crítica nietzschiana ao ginásio era um alerta

para o pecado original que a pedagogia cometia contra o espírito do educando, exigindo que eles produzissem redações a partir de uma lista de temas; essa atividade, além de estéril, comprometia todo texto literário que ele porventura vinha a escrever. Além desses assuntos vagos e gerais, o professor incitava que o aluno dissertasse sobre obras poéticas e problemas éticos ou, então, descrevesse personagens históricas, na forma de uma "pintura de caracteres". Como conclusão da dissertação, o professor pedia ao aluno que fizesse uma apreciação crítica do tema selecionado. Tudo isso diante de indivíduos surpresos e indecisos, perturbados pela enorme variedade de assuntos. (1991, p. 97, grifos nosso).

\section{E ainda que o professor}

exigia a originalidade e o enfoque pessoal dos alunos, mas a originalidade, em última instância, ficava reduzida à escolha numa lista de temas. Reprovando, sobretudo, a forma exagerada de se expressar e a autonomia do pensamento - ou seja, tudo o que, no modo de ver de Nietzsche, é próprio dos muito jovens. (Idem, ibidem, p. 97, grifos nosso).

E finaliza dizendo que nos ginásios,

louvava-se principalmente aquilo que estivesse de acordo com os pontos de vista do professor. O professor se comportava como juiz, julgando sem parcimônia os que tinham e os que não tinham talentos. Desses veredictos, feitos às pressas, saíam os jornalistas e os maus romancistas, os que se apropriavam dos métodos, dos truques e do tom superior de seus professores. Obtendo-se, assim, uma "mediocridade uniforme". (Idem, ibidem, p. 97; grifos nosso).

Por causa dessa nociva metodologia de ensino, implantada no ginásio alemão pelos profissionais de erudição, os ginasianos aprendiam a falar dos espíritos eminentes com superioridade pueril, como nos mostra Nietzsche:

No ginásio, os alunos aprendem a falar do nosso Schiller único com uma superioridade pueril; no ginásio, se lhes habituam a rir dos seus esboços mais nobres e mais alemães, do marquês de Posa, de Max e de Thekla - um riso que provoca a cólera do gênio alemão e do qual se envergonhará uma posteridade melhor. (2012a, p. 83-84). 
Por tudo isso, a educação no ginásio, segundo Nietzsche, deveria "reprimir as ridículas pretensões de autonomia de julgamento e apenas habituar o jovem a uma estrita obediência sob a autoridade do gênio" (2012a, p. 86) - que, ensinando de forma harmoniosa os clássicos alemães, latinos e gregos, contribuiria para o nascimento de asas que elevaria os jovens às alturas, facilitando a ascensão da verdadeira autonomia intelectual que os colocariam em uma posição privilegiada.

$\mathrm{Na}$ visão nietzschiana, "a cultura começa por um caminho correto da língua" (NIETZSCHE, 2012a, p. 90), e este caminho é construído a partir de um olhar atento e um abraço caloroso nos clássicos, pois era por meio da sua beleza e do seu estilo que o ginásio seria estimulado a adquirir "o hábito de usar com seriedade e rigor artístico a sua língua materna" (Idem, ibidem, p. 92).

Se os ginasianos não levasse isso em consideração, continuariam estéreis e nada de profundo sairia do seu ventre, pois, tentar gerar cultura com um abraço gélido nos clássicos ou na ausência deles, era dar um salto no vazio, fazer incultura, assassinar os Helenos e se limitar aos escritos medíocres de época como nos mostra Nietzsche:

Para o ginasiano de hoje, os Helenos enquanto Helenos estão mortos: certamente ele se diverte lendo Homero, mas um romance de Spielhagen o prende bem mais: certamente ele bebe com algum prazer a tragédia e a comédia gregas, mas um drama bem moderno, como Os Jornalistas de Freitag, o toca de maneira absolutamente diferente. (2012a, p. 94).

Por tudo isso, o gymnasium alemão ficava debilitado por uma doença deformante que enfraquecia a educação e asfixiava a cultura. E o único remédio capaz de transfigurar tal enfermidade era tratar com seriedade os clássicos, pois, segundo Nietzsche, só se alça voo e respira-se ar puro por meio de uma "cultura superior, apoiada sobre os pilares da Antiguidade" (2012a, p. 100).

\section{POR ONDE E A PARTIR DE QUE SE INICIA A REFORMA DA EDUCAÇÃO ALEMÃO?}

\subsection{A reforma pelo ginásio}

Uma vez que o espírito da antiguidade estava ausente dos estabelecimentos de ensino, Nietzsche propôs a ideia de que o ginásio objetive a cultura clássica, e 
que todas as outras instituições possam medir por esta visão, pois, elas sofriam com os desvios de sua tendência (a do ginásio), e assim seriam também purificadas e renovadas com sua purificação e renovação (NIETZSCHE, 2012a, p. 80).

Essa ideia era defendida pelo filósofo de Röcken por entender que a reforma da educação das instituições de ensino na Alemanha teria que se dar pelo ginásio, uma vez que nem mesmo a Universidade podia pretender esta importância de centro motriz, já que, na sua constituição, ela não era, num aspecto essencial, senão a culminação da tendência do ginásio. (NIETZSCHE, 2012a, p. 80).

Nietzsche não visava essa reforma através da universidade por entender que a mesma cresceu e envelheceu de forma tão intensa na barbárie, que uma investida por meio dela seria desperdiçar tempo e energia, uma vez que os espíritos dos que a constituíam estavam desgastados pela decadência da época.

Por conta disso, ele volta o olhar para o ginásio - que, embora estivesse também debilitado pela enfermidade da época, tal doença ainda não o tinha consumido por completo, uma vez que ele era constituído por espíritos jovens que, após serem renovados e purificados, estariam prontos a migrarem para a universidade, contribuindo para que ela deixasse de ser um ambiente castrador e embrutecedor, se tornando verdadeiramente o lugar consagrado a toda cultura nobre e superior.

Esse olhar de Nietzsche para o ginásio não é tão difícil de compreender se levarmos em consideração que é na juventude que vigor e resistência conseguem perdurar com mais intensidade perante as enfermidades, dando uma possibilidade maior para o restabelecimento, o que não acontece com um espírito mais velho que passou a maior parte do tempo sendo vítima da doença.

\subsection{A reforma a partir do gênio}

Se pelo ginásio a reforma das instituições de ensino se daria, era a partir do gênio grego que esse processo de transformação se iniciaria. Pois

enquanto a necessidade mais nobre do verdadeiro gênio alemão não procurar a mão deste gênio grego como um firme apoio no rio da barbárie, enquanto este espírito alemão não exprimir aquela nostalgia angustiante pelos Gregos, enquanto a perspectiva da pátria grega, penosamente alcançada, fonte de deleite para Goethe e para 
Schiller, não se tiver tornado o lugar de peregrinação dos homens melhores e mais bem dotados, nesse caso, o ginásio se proporá na cultura clássica um objetivo incoerente, que flutua ao sabor dos ventos [...] (NIETZSCHE, 2012a, p. 98-99).

Essa reforma só seria possível se o gênio alemão primeiramente fosse renovado e purificado de forma profunda e poderosa por meio do gênio grego (NIETZSCHE, 2012a, p. 101), para que "os pensamentos rasteiros, aflitos com pernas de pau, impróprios para o voo" (Idem, ibidem, p. 105), pouco a pouco fossem extirpados dos estabelecimentos de ensino, fazendo brotar a mais cintilante cultura: a que defende com vigor e veemência a natureza aristocrática do espírito "de indivíduos selecionados, munidos das armas necessárias para a realização das grandes obras que ficarão [...]" (Idem, ibidem, p. 105).

\section{CONSIDERAÇÕES FINAIS}

A posição contrária de Nietzsche aos profissionais de erudição tinha como objetivo subjugar a "filosofia de brinquedo" e a "pseudofilosofia" (NIETZSCHE, 1978, p. $73, \S 4)$ que não contribuíam para o combate ao falso saber que se cristalizava em seu tempo.

A proposta desse filósofo era a formação de homens potencialmente virtuosos que imergissem "na profundeza da existência, com uma série de perguntas insólitas nos lábios: - por que vivo? que lição devo aprender da vida? como me tornei assim como sou e por que sofro então com esse ser-assim?" (NIETZSCHE, 1978, p. 75, § 4).

Por isso seu desejo em fazer do ginásio uma escola voltada para a verdadeira cultura, seguindo a mesma proeza que o filólogo Friedrich August Wolf (1759-1824), quando outrora realizou uma reforma do ensino médio na Alemanha, no qual privilegiou os estudos clássicos, introduzindo

nos ginásios o novo espírito que vinha da Grécia e de Roma [...] sua iniciativa ousada teve sucesso em impor uma nova imagem do ginásio, que não deveria mais ser unicamente um viveiro para a ciência, mas sobretudo o lugar consagrado a toda cultura nobre e superior. (NIETZSCHE, 2012a, p. 95-96).

Esse espelhar-se do filósofo de Röcken no eminente Wolf se dava por ele perceber "o singular estado de miséria que acometia o mais importante dos 
estabelecimentos de ensino, o ginásio" (NIETZSCHE, 2012a, p. 99), a fim de que as forças mais sadias vindas da antiguidade clássica dessem as armas "para o combate contra a barbárie do presente" (Idem, ibidem, p. 100), fazendo do ginásio a nova geração ascendente para o que é verdadeiramente alemão, como nos mostra o próprio Nietzsche:

\footnotetext{
Arrastar nesta luta uma escola voltada para a verdadeira cultura e inflamar, particularmente no ginásio, a nova geração ascendente para o que é verdadeiramente alemão, eis a atividade futura que esperamos da escola: onde, enfim, o que deve ser chamado de cultura clássica encontrará também um solo natural e o seu único ponto de partida. (2012a, p. 101).
}

Por tudo isso, fica evidente que a crítica que Nietzsche fez aos estabelecimentos de ensino na Alemanha do século XIX foi uma denúncia dos equívocos existentes na educação dessa nação e ao mesmo tempo uma reivindicação de formação que não se limitasse a pensamentos rasteiros, mas que proporcionasse aos homens mais ousados a verdadeira superação da decadência cultural que embargava a aparição do gênio: senhor de seus instintos e de si mesmo, que não pensa e não age como animal de rebanho, mas como homem que sabe germinar a vida em prol do florescimento e expansão da mesma - não superestimando todo e qualquer tipo de conhecimento que o desvincula dela.

\section{REFERÊNCIAS}

AMARAL. Susana de Castro. As conferências de Nietzsche sobre educação: a diferença entre bildung e gelehrsamkeit. In. Rev. Fragmentos de Cultura, Goiânia, v. 18 , n. 5/6, p. 375-382, maio/jun. 2008.

ASTOR, Dorian. Nietzsche. Tradução de Gustavo de Azambuja Felix. Porto Alegre: Editora L\&PM, 2013.

BARRENECHEA, Miguel Angelo de. Nietzsche e a liberdade. $2^{a}$ ed. Rio de Janeiro: Editora 7 Letras, 2008.

CASANOVA, Marco Antônio. O instante extraordinário: vida, história e valor na obra de Friedrich Nietzsche. Rio de Janeiro: Forense Universitária, 2003.

CAVALCANTI, A. H. Símbolo e alegria: a gênese da concepção de linguagem em Nietzsche. São Paulo: Annablume, 2005. 
DELEUZE. Gilles. Nietzsche e a filosofia. Tradução de Antônio M. Magalhães. Porto: RÉS Editora, 1989.

DIAS, R. M. Nietzsche educador. São Paulo: Editora Scipione, 1991.

DELBÓ, A. Nietzsche e Burckhardt: Estado, crueldade da natureza e da cultura. In. Estudos Nietzsche, Curitiba, v. 1, n. 2, p. 287-310, jul./dez. 2010.

DEBONA, Vilmar. Para não figurarmos como produtos de fábrica: Schopenhauer, Nietzsche e as noções de "caráter adquirido" e de "tornar-se o que se é". In.

Estudos Nietzsche, Curitiba, v. 4, n. 2, p. 157-180, jul./dez. 2013.

FOUCAULT, Michael. Nietzsche, a genealogia a história. In: Microfísica do poder. São Paulo: Graal, 2005.

GIACOIA JUNIOR, O. Folha explica - Nietzsche. São Paulo: Editora Publifolha, 2000. Janeiro, 2005.

. Nietzsche \& para além do bem e mal. Jorge Zahar Editora. Rio de Nietzsche: o humano como memória e como promessa. Petrópolis: Vozes, 2013.

JASPERS, K. Nietzsche. Berlim: Walter de Gruyter \& Co, 1950

JANZ, C.P. Nietzsche: infancia y juventud. Madri: Alianza, 1997.

KOFMAN, Sarah. Os conceitos de cultura nas extemporâneas ou a dupla dissimulação. In: Nietzsche hoje?. MARTON, Scarlet (org.). São Paulo: Brasiliense, 1985.

LIMA, S. C. F. A concepção de formação em Nietzsche: uma leitura de "Schopenhauer como educador". In: Comunicações (UNIMEP), Piracicaba, v. 19, n. 2, p. 45-59, jul./dez. 2012.

MARTON, Scarlett. Nietzsche das forças cósmicas aos valores humanos. Editora Unijui, 1996.

MACHADO, R. Nietzsche e a verdade. Rio de Janeiro: Graal, 1999.

MARQUES, Antonio. A filosofia perspectivista de Nietzsche. São Paulo: Discurso Editorial, 2003.

MOURA, Carlos. Nietzsche: civilização e cultura. São Paulo: M. Fontes, 2005.

MANIERI, D. O senso crítico em Nietzsche. In. Rev. Fragmentos de Cultura, Goiânia, v. 17, n. 1/2, p. 61-75, jan/fev. 2007. 
MARTINS, J. S. Expressividade e criatividade na estética de Nietzsche. In. Rev. Fragmentos de Cultura, Goiânia, v. 20, n. 9/10, p. 591-608, set/out. 2010.

MEDRADO, Alice. O texto natural: sobre a tarefa nietzschiana de "retraduzir o homem de volta à natureza". In. Estudos Nietzsche, Curitiba, v. 5, n. 2, p. 167-188, jul./dez. 2014.

NIETZSCHE, Friedrich. Obras incompletas. Tradução e notas de Rubens Rodrigues Torres Filho. São Paulo-SP: Editora Abril cultural, 1978 - 2ª ed.

. O livro do filósofo. Tradução de Ana Lobo. Porto: Rés, 1984.

. Genealogia da moral. São Paulo: Editora Brasiliense, 1988.

. Ecce homo. Tradução de Paulo Cesár de Souza. São Paulo: Editora Companhia das Letras, 1995.

A filosofia na idade trágica dos gregos. Tradução de Maria Inês Madeira de Andrade. Rio de Janeiro: Elfos; Lisboa: Edições 70, 1995.

Cinco prefácios para cinco livros não escritos. Tradução de Pedro Süssekind. Rio de Janeiro: Sette Letras, 1996. $1996-7^{\mathrm{a}}$ ed.

A Origem da Tragédia. Trad. Ribeiro, A. Lisboa: Guimarães Editores,

Acerca da verdade e da mentira no sentido extranoral. Tradução de Helga Hoock Quadrado. Lisboa: Relógios D’ Água, 1997.

Além do Bem e do Mal. São Paulo: Companhia das Letras, 1999.

Fragmentos finais. Seleção, tradução e prefácio de Flávio R. Kothe. Editoria Universidade de Brasília. Brasília, 2002.

. Da utilidade e desvantagem da história para a vida - II Consideração intempestiva. Tradução de Marco Antônio Casa Nova. Rio de Janeiro: Relume Dumará, 2003.

Assim falou Zaratustra: um livro para todos e para ninguém. Tradução de Mário da Silva. 12a․ ed. Rio de Janeiro: Civilização Brasileira, 2003.

A visão dionisíaca do mundo. São Paulo: Martins Fontes, 2005.

. Humano, demasiado humano. Tradução de Paulo César de Souza. São Paulo: Companhia das Letras, 2005.

Crepúsculo dos ídolos: ou como se filosofa com o martelo. São Paulo: Cia das Letras, 2008. 
Fragmentos póstumos (1869-1874). Tradução de Luis E. de Santiago Guervós. 2ª ed. Madrid: Tecnos, 2010. v. I.

\section{. Escritos sobre educação - Sobre o futuro dos nossos}

estabelecimentos de ensino. Tradução e notas de Noéli Correia de Melo Sobrinho. Rio de Janeiro/São Paulo: PUC-Rio/Loyola, 2012a - 6 ${ }^{\underline{a}}$ ed.

Escritos sobre educação - III Consideração intempestiva:

Schopenhauer educador. Traduçao e notas de Noéli Correia de Melo Sobrinho. Rio de Janeiro/São Paulo: PUC-Rio/Loyola, 2012b - 6ª ed.

PASCHOAL, A. E. Nietzsche: a boa forma de retribuir ao mestre. In: Rev. Filos., Aurora, Curitiba, v. 20, n. 27, p. 337-350, jul./dez. 2008.

STERN, J.P. As ideias de Nietzsche. Trad. Cajado, O. São Paulo: Cultrix, 1978.

SALOMÉ, L.A. Nietzsche em suas Obras. São Paulo: Brasiliense, 1992.

SAFRANSKI, Rüdiger. Nietzsche, biografia de uma tragédia. Tradução de Lya Lett Luft. São Paulo - SP: Geração Editora, 2001.

TONGEREN, P. van. O filósofo como clínico da crítica à cultura. In. Estudos Nietzsche, Curitiba, v. 1, n. 2, p. 265-286, jul./dez. 2010.

VERNANT, J.-P. As origens do pensamento grego. Tradução de I. B. B. Fonseca. 7. ed. Rio de Janeiro: Bertrand Brasil, 1992.

WEBER, J. F. Formação (Bildung), educação e experimentação em Nietzsche. Londrina: Eduel, 2011. 